CDI

14,3

204

Received 26 November 2008 Revised December 2008 Accepted 22 December 2008

\title{
Burnout: 35 years of research and practice
}

\author{
Wilmar B. Schaufeli \\ Utrecht University, Utrecht, The Netherlands \\ Michael P. Leiter \\ Acadia University, Wolfville, Canada, and \\ Christina Maslach \\ University of California at Berkeley, Berkeley, California, USA
}

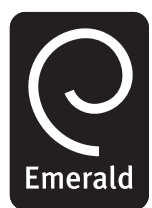

Career Development International Vol. 14 No. 3, 2009 pp. $204-220$

(c) Emerald Group Publishing Limited 1362-0436

DOI $10.1108 / 13620430910966406$

\begin{abstract}
Purpose - The purpose of this paper is to focus on the career of the burnout concept itself, rather than reviewing research findings on burnout.

Design/methodology/approach - The paper presents an overview of the concept of burnout.

Findings - The roots of the burnout concept seem to be embedded within broad social, economic, and cultural developments that took place in the last quarter of the past century and signify the rapid and profound transformation from an industrial society into a service economy. This social transformation goes along with psychological pressures that may translate into burnout. After the turn of the century, burnout is increasingly considered as an erosion of a positive psychological state. Although burnout seems to be a global phenomenon, the meaning of the concept differs between countries. For instance, in some countries burnout is used as a medical diagnosis, whereas in other countries it is a non-medical, socially accepted label that carries a minimum stigma in terms of a psychiatric diagnosis. Originality/value - The paper documents that the exact meaning of the concept of burnout varies with its context and the intentions of those using the term.
\end{abstract}

Keywords Stress, Social change, Medical diagnosis

Paper type General review

Job burnout emerged as an important concept in the 1970s, and it captured something very critical about people's experience with work. It continues to do so today, some 35 years since its introduction to psychological literature and to cultural discourse. Both then and now, burnout has been a concept that seems to ring true to a common experience among people. It has inspired researchers to study it and try to better understand what it is and why it happens. It has inspired practitioners to figure out ways to cope with it, prevent it, or combat it. Thus, from the beginning, burnout has enjoyed a joint recognition from both researchers and practitioners as a social problem worthy of attention and amelioration. As this recognition has spread to many other countries, beyond its American origins, it has become a phenomenon of notable global significance.

Currently, burnout is a well-established academic subject on which thousands of publications have appeared, and about which numerous congresses and symposia are held. We estimate that currently over 6,000 books, chapters, dissertations, and journal articles have been published on burnout (for reviews see: Schaufeli and Enzmann, 1998; Maslach et al., 2001; Halbesleben and Buckley, 2004). The concept of burnout has stimulated research on job stress, particularly in areas like the helping professions, 
which had not been the focus of attention before. It also stimulated theorizing, particularly in the area of emotional labor, symptom contagion, and social exchange.

In the occupational medical setting of some European countries with elaborated social security systems - notably Sweden and The Netherlands - burnout is an established medical diagnosis. This means that it is included in handbooks, and that physicians and other health professionals are trained in assessing and treating burnout. Furthermore, psychologists, social workers, psychiatrists, counselors, human services officers, organizational consultants offer a wide array of interventions, ranging from individual treatment programs, via preventive workshops to organizational consultancy. A concrete example with special relevance for career development is the burnout reducing effect of employee mentoring (Van Emmerik, 2004). In other words, many professionals earn a living by treating burnout victims, giving workshops on burnout, or consulting with organizations on how to prevent burnout and build work engagement. In this sense, burnout has boosted professional practice.

As we look back over 35 years of research and practice, what have been the critical themes, insights and conclusions that have emerged? What accounts for the remarkable longevity of a concept that originally was dismissed as "pop psychology" (Maslach and Schaufeli, 1993). What are the lessons learned, and what are is the current challenge to be addressed?

\section{Understanding the nature of burnout}

As a metaphor for the draining of energy, burnout refers to the smothering of a fire or the extinguishing of a candle. It implies that once a fire was burning but the fire cannot continue burning brightly unless there are sufficient resources that keep being replenished. Over time, employees experiencing burnout lose the capacity to provide the intense contributions that make an impact. If they continue working, the result is more like smoldering - uneventful and inconsequential - than burning. From their own perspective or that of others, they accomplish less. In summary, the metaphor describes the exhaustion of employees' capacity to maintain an intense involvement that has a meaningful impact at work.

The success of the burnout metaphor reflects the concept's origins in general discourse. People used the term to describe an experience before scientific psychology identified it as a phenomenon worthy of study. Freudenberger (1974) borrowed the term from the illicit drug scene where it colloquially referred to the devastating effect of chronic drug abuse. He used the term to describe the gradual emotional depletion, loss of motivation, and reduced commitment among volunteers of the St Mark's Free Clinic in New York's East Village that he observed as a consulting psychiatrist. Such free clinics for drug addicts and homeless people had grown out of the counter-movement against the establishment. Not unimportantly, Freudenberger himself fell victim to burnout twice, which increased his credibility in spreading the message of burnout. His writings on the subject were strongly autobiographical and his impact is illustrated by the fact that in 1999, he received The Gold Medal Award for Life Achievement in the Practice of Psychology at the APA Convention in Boston.

Independently and simultaneously, Maslach and her colleagues came across the term in California when interviewing a variety of human services workers. As a social psychological researcher, Maslach was interested in how these workers coped with their emotional arousal using cognitive strategies such as detached concern. As a result of 
CDI

14,3

206 these interviews she learned that these workers often felt emotionally exhausted, that they developed negative perceptions and feelings about their clients or patients, and that they experienced crises in professional competence as a result of the emotional turmoil (Maslach, 1976, 1993). These practitioners referred to this syndrome as "burnout".

In a thorough process of interviews, observation, and psychometric development, Maslach and her colleagues developed a method for assessing burnout as a multidimensional construct that went beyond mere exhaustion (Maslach and Jackson, 1981; Maslach et al., 2008). At the outset, burnout was predominantly identified within the human services: "Burnout is a syndrome of emotional exhaustion, depersonalization, and reduced personal accomplishment that can occur among individuals who work with people in some capacity" (Maslach et al., 1996, p. 4). However, by the late 1980s, researchers and practitioners began to recognize that burnout occurred outside the human services, for instance, among managers, entrepreneurs, and white- and blue collar workers. Thus, the burnout metaphor was extended from the intense requirements of client service to other work requiring creativity, problem solving, or mentoring. In this more general form, burnout was defined as "... a state of exhaustion in which one is cynical about the value of one's occupation and doubtful of one's capacity to perform” (Maslach et al., 1996, p. 20).The term burnout, then, was transferred from a literal reference to a depletion of physical resources supporting combustion to the psychological domain. But why did burnout suddenly gain momentum in the USA in the mid 1970s in the first place, and why does it continue to remain an important and popular issue?

\section{The social and cultural context of emerging burnout}

When burnout began to be described and discussed in the 1970s, it was primarily in reference to work in the human services, such as health care, social work, psychotherapy, legal services, and police work. Qualitative interviews and case studies gave a vivid picture of the experience in which people lost both their energy and their sense of the value of their job. The loss of meaning was especially poignant within professions dedicated to lofty goals to help and serve others. Tellingly, burnout discussions began within the human services, because they were better able to give "voice" to issues of emotions, values, and relationships with people - concepts that had not been widely recognized within the research literature on the workplace.

The roots of the burnout concept seem to be embedded within several broad social, economic, and cultural developments of the 1960s in the USA. Below we summarize these developments whose impact on burnout is - by their very nature - speculative rather than empirically demonstrated.

In the early 1960s, President John F. Kennedy ignited a vision of public service, as he challenged Americans to "ask not what your country can do for you, but ask what you can do for your country". Subsequently, President Lyndon B. Johnson launched the "War on Poverty" that caused a large influx of idealistically motivated young people into human services professions. However, after struggling to eradicate poverty for a decade or so, they found themselves increasingly disillusioned. They came to learn that the systemic factors perpetuating poverty nullified their efforts to alleviate poverty's downstream impact on people and frustrated their efforts to open opportunities for children of poor families. Frustrated idealism was a defining quality of the burnout experience, mirroring the intensity of combustion. It was critical to the concept's 
momentum: service providers were appalled at their diminished capacity to perform or to show compassion towards their recipients. The experience of burnout was not merely an inconvenience or an occupational hazard, but a devastating attack on their professional identity. They had chosen a career path of service, forsaking other options in the vibrant American economy of the era. Exhaustion on its own would not be so compelling: dedicated people may even derive fulfillment from exhausting themselves through exerting extraordinary effort for a deeply valued cause. The lack of compassion and diminished effectiveness implicit in the full burnout experience had a much more devastating impact on their identity (Farber, 1983).

From the 1950s onwards the human services in the USA as well as in Europe rapidly professionalized and bureaucratized as a result of greater government and state influence. Small-scale, traditional agencies where work was considered a calling, transformed into large-scale modern organizations with formalized job descriptions. Arguing this point, Cherniss and Kranz (1983) observed that burnout was virtually absent in monasteries, Montessori schools, and religious care centers where people consider their work as a calling rather than merely a job. They argued that such "ideological communities" provide a collective identity that prevents burnout from occurring because of social commitment, a sense of communion, contact with the collective whole, and shared strong values. Seen from this perspective, burnout represents the price paid of professionalizing the helping professions from "callings" into "modern" occupations. The frustration and disillusionment arising from a widespread, institutionalized clash of utilitarian organizational values with providers' personal or professional values contributed further to burnout.

The "cultural revolution" of the 1960s weakened the professional authority of among others - doctors, nurses, teachers, social workers and police officers. The traditional prestige of these professionals was no longer evident after the 1960s. Simultaneously, empowered recipients expected much more than ever before. As a consequence, recipients' demands of care, service, empathy, and compassion intensified. Together, these two trends increased the technical and emotional demands of professional work considerably. Even if they relinquished professional ideals, embracing the values of institutionalized services, service providers were unlikely to experience fulfillment from their work. From the perspective of social exchange, a discrepancy grew between professionals' efforts and the rewards they received in recognition and gratitude. This "lack of reciprocity" is known to foster burnout (Schaufeli, 2006).

The three factors mentioned so far are more or less specific for the human services, the occupational group where burnout was observed first. However, there were additional socio-cultural developments that seem to have contributed to the emergence and proliferation of burnout in the mid-1970s as well. Since the Second World War, traditional social communities and networks such as the church, the neighborhood, and the family have gradually eroded. According to Sennett (1998) this is the result of the emerging "flexible capitalism" that replaces traditional rigid, homogeneous and predictable social institutions by more flexible, heteronymous and continuously changing ones. This development encourages social fragmentation and what he calls "the corrosion of character," a notion somewhat similar to burnout. Not only has community support decreased, but increasingly, individualism has prospered. People have created personal definitions of their own social and occupational roles because society no longer has provided shared definitions. In parallel, a "narcissistic culture" 
CDI

14,3

208
(Lasch, 1979) developed that is characterized by transient, unrewarding and even combative social relationships that produce self-absorbed, manipulative individuals, who demand immediate gratification of their desires but remain perpetually unsatisfied. As Farber (1983, p. 11) noted, the combination of the trends toward individualization and towards narcissism produces "a perfect recipe for burnout": the former produces stress and frustration while the latter undermines people's coping resources.

An overarching development that includes many of the previous issues and that seem to have fostered burnout is the rapid and profound transformation from an industrial society into a service economy that took place in the last quarter of the past century. This social transformation goes along with psychological pressures, which, in their turn, are subject to public discourse. A striking parallel exists with neurasthenia - literally, weakness of the nervous system - that was first observed at the end of the nineteenth century when American society transformed from an agricultural into an industrial society (Loriol, 2002). Tellingly, neurasthenia appeared first among the icons of the new industrial era - the dynamic business men - like burnout appeared similarly first among the icons of the new service era - the human services professionals. To George Beard, who coined the term in 1869, neurasthenia was the product of rapid technological change as expressed, for instance, by the telegraph (Cooper and Dewe, 2004, p. 5), whereas for Freudenberger (1974) and Maslach (1976), burnout was the product of rapid change in social relationships. Although this particular constellation of political, social, and cultural developments in the USA seem to have set the stage for the concept of burnout, what sustains burnout's momentum in the twenty-first century?

\section{Burnout in the twenty-first century}

Burnout was originally viewed as a specific hazard for naïve, idealistic, young service professionals who became exhausted, cynical, and discouraged through their experiences in cold bureaucratic systems serving entitled, unresponsive clients with intractable problems. But that was long ago. The young idealists entering the workforce in the 1960s are at the time of this writing heading toward retirement. Young professionals in the early twenty-first century have fewer opportunities for naivety. Television dramas give thoroughly gritty depictions of work life. A favorite and repeated theme is the novice's loss of innocence. Professional training programs for service professionals, MBAs, and lawyers rarely paint a rosy picture. And the internet provides an incessant stream of unfiltered and only occasionally corroborated information on any topic imaginable (and a few that defy imagination). People have few illusions about the working world. But they are nevertheless vulnerable to burnout (Cho et al., 2006; Gellert and Kuipers, 2008). And the boomers who have been working since the 1970s, and who should know better by now, are vulnerable as well (Leiter et al., 2008). It may be that while naïve idealism magnifies one's vulnerability to burnout, it is not an essential prerequisite. The deciding factor may be the nature of work life and the broad cultural context within which work occurs in the twenty-first century.

Two distinct contributors to the experience of work life explain burnout's persistence as an experience, a matter of social importance, and a focus of scientific inquiry. The first contributor is a persistent imbalance of demands over resources (Aiken et al., 2001; Bakker and Demerouti, 2007). When demands increase -, e.g. more service recipients with more intense requirements - resources fail to keep pace. There 
are insufficient personnel, equipment, supplies, or space to meet the demand (Aiken et al., 2002). Insufficient opportunities to rest and regenerate depleted energy aggravate the exhausting impact of demand/resource imbalances.

The second contributor concerns motives rather than energy. Employees in the twenty-first century view organizational missions, visions, and values with skepticism (Hemingway and Maclagan, 2004). Employees may hold personal values that differ from the organizations. For example, a retail salesperson may be more interested in the quality of customer service than meeting sales targets. Another salesperson may only value maximizing personal sales commissions over developing ongoing relationships with customers. In some circumstances, more clearly articulated corporate values may provide a more fertile ground for value conflicts.

The potential for value conflicts is increased as organizations and employees reduce their commitment to one another. The major value conflict for service professionals in the 1970s was between the counterculture and an established social order (Martin and Siehl, 1983). Young people distrusted older generations. They did not trust anyone over 30 and they did not trust their institutions either. The free clinic movement in the USA sought to establish a new approach to health care. Working for organizations in the establishment engendered one type of value conflict. Working for organizations within the counterculture engendered another type of value conflict as the demands of business or public sector accountability were generally inconsistent with counterculture ideals.

Professional service providers or managers entering a twenty-first century workforce expect a much more varied career than their counterparts a generation previously (McDonald et al., 2005). Neither party is ready to make a life-long commitment. Accordingly, employees are less willing to put aside their personal inclinations for the good of the company.

Another form of conflict occurs between the organization's stated values and its values in action (Argyris, 1982). Employees exercise severe judgment when they witness a gap between organizational intentions and reality. Rather than attributing the shortfall to market conditions or bad luck, they often attribute the problem to corporate hypocrisy. This attribution may apply to the entire executive level or it may pertain to distinct individuals who are abusing positions of authority to exploit the company for their personal gain. In these scenarios, employees accept the organizations' espoused values. They experience conflict with the values they attribute to the organizations' shortcomings.

Public sector organizations in the twenty-first century often state ideals that far exceed their resources (Potter et al., 2007). Few societies devote sufficient resources to meet their populations' needs. The systemic imbalance of demands to resources promotes exhaustion and reduces professional efficacy while alienation from corporate values reduces providers' involvement in their work or their service recipients (Schaufeli, 2006; Schaufeli and Bakker, 2004). Together, the principles inherent in globalization promise to perpetuate burnout throughout information/service organizations.

Current management within a globalized economy proclaims lofty ideals that they fail to support while they focus on the fiscal, policy, and political issues required to maintain large organizations or corporations. As individuals struggle to chart a course through complex, contradictory, and sometimes hostile institutional environments, they are vulnerable to the exhaustion, cynicism, and inefficacy that define burnout. 
CDI

14,3

210
The burnout phenomenon has grown from a specialized occupational hazard to a pervasive workplace hazard.

Thus, it appears that the same basic factors seem to drive burnout now as before, albeit with a slightly different quality. Most prominent are the imbalance between demands and resources at work, and the conflict between values (i.e. between personal values and those of the organization, and between the officially stated organizational values and the values in action).

\section{The globalization of burnout}

During the past 35 years, burnout has attracted the attention of researchers, practitioners and the general public almost anywhere around the globe. Despite methodological problems, such as sampling bias, quantitative studies suggest that burnout is not exclusively a North American or Western phenomenon (Golembiewski et al., 1996; Perrewé et al., 2002; Savicki, 2002). For instance, a bi-cultural analysis of American and Philippine nurses showed that the social work environment as well as national value systems influences burnout-levels in both countries (Turnipseed and Turnipseed, 1997). In a similar vein, Pines (2003) showed that despite different value systems burnout was prevalent in Jewish and Arab Israelis. After its initial emergence in the USA in the 1970s, the concept was introduced in the 1980s in Western Europe, particularly the UK, the Low countries (Holland and Belgium), Germany, and the Nordic countries (Scandinavia and Finland), as well as in Israel. From the mid 1990s onwards burnout was also studied in the rest of Western and Eastern Europe, Asia, the Middle East, Latin America, Australia, and New Zealand. Finally, after the turn of the century, research on burnout spread to Africa, China, and to the Indian subcontinent. It is interesting to note that, roughly speaking, the order in which the interest in burnout seems to have spread corresponds with the economic development of the countries involved. For instance, currently, the economies of India and China are booming, and burnout now seems to attract attention in these countries as well. It has been suggested that globalization, privatization, and liberalization cause rapid changes in modern working life, such as increasing demands of learning new skills, the need to adopt new types of work, pressure of higher productivity and quality of work, time pressure and hectic jobs, which, in their turn, may produce burnout - particularly in rapidly developing countries like India (Kulkarni, 2006).

The fact that burnout occurs globally does not necessarily imply that the meaning of the term is identical across countries and languages. A non-exhaustive overview reveals that the term "burnout" is used quite differently in various languages. Although in some languages equivalents of "burnout" or "to burn out" exist, often the English term is preferred[1]. In other languages, a more or less free translation of the English "burnout" is used by the lay public[2], whereas in these countries professionals and scholars use the "scientific" English term. Also, instead of "burnout" the notion of "exhaustion" is used, sometimes in conjunction with the adjective "professional" to denote its work relatedness[3]. Quite interestingly, in yet some other languages the connotation of the English term "burnout" - or its local equivalent - is considered too strong, implying the impossibility to recover, i.e. a psychological death sentence. For that reason a somewhat milder term - usually referring to exhaustion - is used[4]. Moreover, in some languages "exhaustion" denotes the process of burnout that includes its milder forms as well, whereas "burnout" is used for the end-stage of that 
process. This is at odds with the original use of "burnout" which was thought to cover the entire range running from mild to severe symptoms.

JIn addition to linguistic reasons, the local social context plays a major role in the way burnout is viewed. Namely, in some countries a formal burnout diagnosis opens the possibility for the individual to profit from financial compensation arrangements, counseling, psychotherapeutic treatment, and rehabilitation. In other countries, however, a formal burnout diagnosis is not recognized, and burned-out employees are not eligible for compensation or treatment of any kind. It is not surprising that, in the former instance, "burnout" developed into a formal medical diagnosis, the end-stage of a process. Notably this is the case in Sweden and the Netherlands. In these countries, "burnout" is an issue in the medical consulting room, as is, for instance, diabetes or hypertension.

\section{Burnout as social problem or medical diagnosis}

The "medicalization" of burnout is intertwined with recent debates about whether burnout should be considered as exhaustion, and no more. This "exhaustion-only" view has been expressed by both some researchers and some practitioners. Most scientific research uses the three-dimensional description of exhaustion, cynicism, and inefficacy that is implied in the Maslach Burnout Inventory (MBI - Maslach and Jackson, 1981). The MBI clearly dominates the field: by the end of the 1990s it was used in 93 per cent of the journal articles and dissertations (Schaufeli and Enzmann, 1998, p. 71). Although meanwhile some alternative burnout instruments appeared the scene, such as the Copenhagen Burnout Inventory (Kristensen et al., 2005) and the Oldenburg Burnout Inventory (Demerouti et al., 2002), the MBI remains the "gold standard" to assess burnout. Practically speaking, the concept of burnout concurs with the MBI, and vice versa. Despite the supremacy of the MBI in scientific research, a debate among scholars on the nature of burnout continues (see the special issue of Work \& Stress, Vol. 19 (3), 2005). This debate revolves around two interrelated issues: the dimensionality of burnout and its scope. Some critics maintain that rather than being a multi-dimensional phenomenon, burnout is essentially equivalent to exhaustion (Pines and Aronson, 1981; Kristensen et al., 2005; Shirom and Melamed, 2005). For those in favor of the one-dimensional view, exhaustion is the one and only hallmark of burnout. Although theoretically speaking various aspects of exhaustion have been identified - for instance, physical, emotional, and mental exhaustion (Pines and Aronson, 1981), or physical and psychological exhaustion (Kristensen et al., 2005), or physical fatigue, emotional exhaustion, and cognitive weariness (Shirom and Melamed, 2005) - self-report measures inevitably produce one single overriding exhaustion factor. Champions of the exhaustion-only perspective argue that constructs that emerge inductively from factor-analyses - like the MBI - are conceptually inferior to constructs derived from theoretical frameworks. This criticism ignores the iterative process through which Maslach and her colleagues developed the MBI through extensive, in-depth interviews (Maslach and Schaufeli, 1993). This conceptual work produced items reflecting a three-dimensional construct that was confirmed statistically. The insistence of contrarily-minded researchers to label exhaustion as burnout reflects the power of the metaphor. Chronic exhaustion - physical or mental is a legitimate label for problems encountered by many people within or outside the working world. However, there is no scientific reason to use the term, burnout, when referring to exhaustion only. But burnout is such a catchy metaphor, reflecting a broad 
CDI

14,3

212

cultural experience that it is difficult to relinquish. Hence, our view is that reducing burnout to mere exhaustion boils down to putting new wine (burnout) in very old bottles (workplace fatigue).

As for the scope of burnout, some scholars consider burnout as a generic, context-free phenomenon that may occur outside work. For instance, recently Kristensen et al. (2005, p. 197) proposed to discriminate between work-related burnout, client-related burnout, and personal burnout. The latter is described as "...the degree of physical and psychological fatigue and exhaustion experienced by the person”. In their view personal burnout may also occur among those who do not work such as young people, unemployed, early retired people, pensioners, and housewives. As a matter of fact, the assumption that burnout is a context-free phenomenon has a history that goes back to the early days of burnout research and does accompany it since (e.g. Pines and Aronson, 1981). However, a multi-dimensional approach as in the $\mathrm{MBI}$ is by definition incompatible with the notion of context-free burnout. Then in any context - at work or outside work - people may feel exhausted, but cynicism and reduced professional efficacy refer to a particular object (i.e. one is cynical about something and feels inefficacious to do something). A retired or unemployed person may feel exhausted, but it is impossible to identify the "something" about which unemployed or retired people should feel cynical or inefficacious. Hence, arguing that burnout is a generic, context-free phenomenon goes necessarily hand in hand with a limited definition of burnout as the equivalent to exhaustion. This approach not only simplifies the concept, but it effectively - as we noted above - puts new wine in old bottles. To conclude, although in practice the three-dimensional conceptualization of burnout is used by the overwhelming majority of researchers, not all of them mean the same thing when they refer to "burnout."

The MBI defines burnout as a matter of degree on its three subscales. This quality is compatible with regression-based statistical methods, and current statistical developments, such as structural equation modeling, manage the three inter-related continuous subscales. Professional practice has less patience with complex continuous measures, though. Practitioners of individual psychological, psychiatric, or medical treatment want to differentiate among people who are "burned out" and those who are not. Medical practitioners favor dichotomous diagnoses, especially when informing decisions on treatment or disability insurance claims. In this way the definition of burnout is shaped by practical questions - Who is to be treated? Who is to receive financial compensation?

Both statistical and diagnostic criteria have been used to transform a continuous burnout inventory - such as the MBI - into a dichotomy that discriminates between burnout "cases" and "non-cases." Statistically, cut-off points are determined, for instance, for "low", "average", and "high" scores, based on the lower, medium, and upper thirds of the score-distribution, as recommended in the test-manual of the MBI (Maslach et al., 1996). However, such cut-offs are based on frequency distributions and therefore do not refer to an external criterion. For example, a score at the 70th percentile on exhaustion is relatively high, but it may not be associated with subjective distress, health disorders, or poor performance.

The diagnostic strategy uses an independently established burnout diagnosis as an external criterion to establish cut-off points. For example, Schaufeli et al. (2001) used neurasthenia, as defined in the International Classification of Diseases (ICD-10, 1994) as 
the equivalent of severe burnout (see also below). According to the ICD-10, a neurasthenic diagnosis (code F43.8) requires:

- persistent and increased fatigue or weakness after minimal (mental) effort;

- at least two out of seven distress symptoms such as irritability and inability to relax;

- the absence of other disorders such as mood disorder or anxiety disorder.

According to Schaufeli et al. (2001), in order to be diagnosed as "burnout," the neurasthenic symptoms should additionally be work-related, and the individual should receive professional treatment. Based on this set of diagnostic criteria, clinically validated cut-off scores for each of the three MBI-sales were established. Additional research confirmed the validity of the MBI cut-off points and also established a decision rule for combining the scores of the three burnout dimensions: an individual is considered to be severely burned-out when he or she has a "highly negative" score on exhaustion in combination with a "highly negative" score on either of the two remaining MBI dimensions (Brenninkmeijer and Van Yperen, 2003; Roelofs et al., 2005). This decision rule allows the transformation of the MBI - a multi-dimensional continuous burnout inventory - into a dichotomy that can be used by practitioners in order to diagnose burnout.

Through this process of dichotomization, burnout gradually expanded from a psychological phenomenon to encompass a medical diagnosis as well, at least in some European countries such as The Netherlands and Sweden. As a result, when practitioners with a psychological background use the term "burnout," they usually refer to the whole spectrum of burnout complaints running from very mild to severe burnout, whereas practitioners with a medical background refer to severe burnout cases that meet these diagnostic criteria. Although medical diagnoses aspire to a clear categorization, the practice is accustomed to integrating multiple sources of information to differentiate among a plethora of potential health problems to produce a diagnosis. As such, rather than simplifying burnout into exhaustion, the diagnostic protocol for burnout integrates diverse information that may include the three MBI subscales to arrive at a dichotomous diagnostic standard.

In Sweden the ICD-10 burnout diagnosis was introduced in 1997, soon after which it became one of the five most common diagnoses and the one that showed the sharpest increase, particularly within the public sector (Friberg, 2006, p. 72). "Burnout" was initially diagnosed according to the ICD-10 - which was translated into Swedish in 1997. The ICD-10 is the officially used diagnostic tool in Swedish health care, without a formal ICD-10 diagnosis the person is not eligible for financial compensation in case of sick-leave or disability. In the ICD-10 diagnostic system burnout (code Z73.0) is placed in the category "problems related to life management difficulty" and loosely described as "a state of vital exhaustion", without further elaboration. This, of course, leaves much room for interpretation for medical professionals. For that reason, in 2005 the Swedish National Board of Health and Welfare has added the "exhaustion disorder" (utmattningssyndrom) to the national version of the ICD-10 (code F43.8). Its criteria are: physiological or mental symptoms of exhaustion for at least two weeks, an essential lack of psychological energy, and symptoms such as difficulties to concentrate, decreased ability to cope with stress, irritability or emotional instability, sleep disturbances, muscle pain, dizziness or palpitations. These symptoms have to occur 
CDI

14,3

214 every day during a two-week period and must cause significant suffering with impaired work capacity. Finally the symptoms must not be related to other psychiatric diagnosis, substance abuse, or medical diagnosis.

In a somewhat similar vein, in The Netherlands in the 1990s, practice guidelines for assessing and treating stress-related disorders in occupational and primary health care were issued by the Royal Dutch Medical Association in 2000 (Van der Klink and van Dijk, 2003). The diagnostic classification of these guidelines distinguish between three levels of stress-related disorders:

(1) distress (i.e. relatively mild symptoms that lead to only partly impaired occupational functioning);

(2) nervous breakdown (i.e. serious distress symptoms and temporal loss of occupational role); and

(3) burnout (i.e. work-related neurasthenia and long-term loss of the occupational role).

Clearly, "burnout" is defined as an end-stage. For both less severe conditions traditional Dutch terms are used spanningsklachten and overspannenheid, respectively). Particularly the connotation of the latter term (literally "overstrain") comes very close to the Anglo-Saxon "burnout". The practice guidelines recommend the use of the clinically validated cut-off points of the MBI as a diagnostic tool for assessing stress-related disorders in occupational and primary health care.

Thus, the definition of "burnout" varies with its context and the intentions of those using the term. Although the three-dimensional definition that is implied in the MBI has achieved almost universal acceptance in research, some apply the term to simple exhaustion. Furthermore, professionals with a psychological background tend to see burnout as a continuous phenomenon, whereas those with a medical background tend to see burnout dichotomously. To the former, burnout is a form of chronic distress that results from a highly stressful and frustrating work environment, whereas for the latter it is a medical condition. Although not necessarily at odds, both types of practitioners refer to slightly different things when referring to burnout.

It has been maintained that the popularity of burnout in North America lies in the very fact that "burnout" is a non-medical, socially accepted label that carries a minimum stigma in terms of a psychiatric diagnosis (Shirom, 1989). Paradoxically, the reverse seems to be true in Europe: burnout is very popular because it is an official medical diagnosis that opens the gates of the welfare state with its compensation claims and treatment programs.

\section{Outlook: the positive future of burnout}

Originally, burnout was defined as a negative state of mind, albeit that one of its three constituting elements - reduced professional efficacy - was measured with positively worded items that were reversed to constitute a negative scale. A broader, more positive perspective emerged in the mid-1990s when Maslach and Leiter (1997) rephrased burnout as an erosion of a positive state of mind, which they labeled engagement. According to Maslach and Leiter (1997, p. 24) the burnout process starts with the wearing out of engagement, when "...energy turns into exhaustion, involvement turns into cynicism, and efficacy turns into ineffectiveness". Accordingly, engagement is characterized by energy, involvement and efficacy - the direct 
opposites of the three burnout dimensions. By implication, engagement is assessed by the opposite pattern of scores on the three MBI scales: unfavorable scores are indicative for burnout, whereas favorable scores are indicative for engagement. By rephrasing burnout as an erosion of engagement with the job the entire range of employee well-being is covered by the MBI running from the positive pole (engagement) to the negative pole (burnout).

Schaufeli and his colleagues took a different approach to the concept of engagement (Schaufeli and Salanova, 2007). They defined and operationalized engagement in its own right. Although they agreed with positioning engagement as the positive antithesis of burnout, they did not accept the operationalization of assessing the state by the opposite profile of MBI scores. Instead, they developed the Utrecht Work Engagement Scale (UWES) to measure vigor, dedication, and absorption as the three dimensions that constitute engagement (Schaufeli et al., 2002). Meanwhile, research showed that the UWES and the MBI are negatively related and that exhausting and vigor, as well as cynicism and dedication each constitute a continuum that was dubbed energy and identification, respectively (González-Romá et al., 2006).

This changing focus in burnout research from an exclusively negative approach to the erosion of a positive psychological state coincides with the emergence of Positive Psychology. Quite symbolically at the brink of the new millennium, in January 2000, a special issue of the American Psychologist sparked interest in Positive Psychology. In that issue, its most prominent advocates, Seligman and Csikszentmihalyi (2000, p. 5), stated that the purpose of Positive Psychology “... is to begin to catalyze a change in the focus of psychology from pre-occupation only with repairing the worst things in life to also building positive qualities". After less than a decade, positive psychology is thriving, including the field of positive occupational behavior, which is defined as "...the study and application of positively oriented human resource strengths and psychological capacities that can be measured, developed, and effectively managed for performance improvement in today's workplace" (Luthans, 2003; p. 179). Although the notion of engagement was formulated a couple of years before the "official" commencement of the positive psychology movement in 2000 and the first empirical studies were carried out before that date, this movement certainly reinforces the interest in work engagement. Then clearly, the concept of work engagement fits neatly into this emerging positive trend and illustrates that the deficit-based study of burnout is complemented with a positive approach that focuses on work engagement. The growing scientific interest for work engagement is exemplified by special issues of leading journals such as the Journal of Organizational Behavior (Bakker and Schaufeli, 2008) and Work \& Stress (Bakker et al., 2008). Moreover, widespread interest in the business community encourages the scientific community's shift towards a positive perspective that rephrases burnout as the erosion of engagement. Today's organizations face rapid and continuous changes. Instead of traditional organizational structures (i.e. control mechanism, chain of command) and a strong emphasis on economic principles (i.e. cost reduction, efficiency, cash flow), the focus in modern organization is on the management of human capital. Currently, organizations expect their employees to be proactive and show initiative, collaborate smoothly with others, take responsibility for their own professional development, and commit to high quality performance. This increased psychologization is illustrated by Ulrich (1997, p. 125), who writes in his seminal book Human Resources Champions, "Employee contribution becomes a critical business issue because in trying 
CDI

14,3

216 to produce more output with less employee input, companies have no choice but to try to engage not only the body but the mind and soul of every employee". Evidently, this objective is not achieved with a work force that is "healthy" in the traditional sense, meaning that employees are symptom-free and do not suffer from physical illness or burnout. In order to thrive, organizations need engaged employees who are motivated, proactive, responsible, and involved. Instead of just "doing one's job," employees are expected "to go the extra mile". So for today's organizations burnout prevention is replaced by the promotion of work engagement. Preventing burnout is not enough, it is necessary to go further to foster work engagement. The practical implications were evident in a recent meta-analysis that convincingly showed the economic benefits of business-units with high average levels of engagement compared to those with lower levels of engagement (Harter et al., 2002).

In sum: it can be concluded that developments in science (the recent emergence of positive psychology) and organizations (increased attention for positive organizational behavior of employees) strengthen the positive turn in burnout research that is the rephrasing of burnout as an erosion of engagement. Seen from this perspective, the future of burnout lies in the realization that it constitutes the negative pole of a continuum of employee well-being, of which work engagement constitutes the opposite positive pole. The scientific challenge for the future will be to uncover in how far different psychological processes are responsible for producing burnout and work engagement. A recent example is the Job Demands Resources model that posits that burnout plays a key role in a health impairment process that is mainly driven by high job demands, whereas engagement plays a key-role in a motivational process that is driven by job resources (Bakker and Demerouti, 2008; Schaufeli et al., in press). As for the practice of burnout, it remains to be seen if corporations and public sector organizations are willing to provide the necessary resources to maintain extraordinary efforts from their employees, or whether efforts to inspire extraordinary efforts become a new source of burnout.

\section{Notes}

1. For instance, in Afrikaans (uitgebrand), Chinese (juandai), Danish (udbrcendthed), Dutch (opgebrand), Finnish (loppuunpalanut), German (ausgebrannt), Italian (bruciare), Japanese (バーン・アウト), Norwegian (utbrenthet), Polish (wypalenie zawodowe), Spanish (quemarse), and Swedish (utbränd).

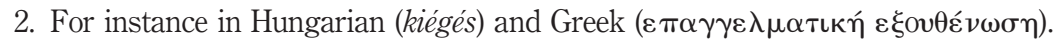

3. For instance in as in French (Épuissement professional), Hebrew (shechika (הקיחש)), Italian, (esaurito), and Portuguese (exaustão).

4. For instance, in Finnish (työuupumus), Hungarian (kimerülés), Norwegian (utmattethet), and Swedish (utmattningssyndrom).

\section{References}

Aiken, L.H., Clarke, S.P., Sloane, D.M., Sochalski, J. and Silber, J.H. (2002), "Hospital nurse staffing and patient mortality, nurse burnout, and job dissatisfaction", Journal of the American Medical Association, Vol. 288, pp. 1987-93.

Aiken, L.H., Clarke, S.P., Sloane, D.M., Sochalski, J.A., Busse, R., Clarke, H., Giovannetti, P., Hunt, J., Rafferty, A.M. and Shamian, J. (2001), "Nurses' reports on hospital care in five countries: the ways in which nurses' work is structured have left nurses among the least satisfied workers, and the problem is getting worse", Health Affairs, Vol. 20, pp. 43-53. 
Argyris, C. (1982), Reasoning, Learning, and Action: Individual and Organizational, Jossey-Bass, San Francisco, CA.

Bakker, A.B. and Demerouti, E. (2007), "The job demands resources model: state-of-the-art", Journal of Managerial Psychology, Vol. 22, pp. 309-28.

Bakker, A.B. and Demerouti, E. (2008), "Towards a model of work engagement", Career Development International, Vol. 13, pp. 209-23.

Bakker, A.B. and Schaufeli, W.B. (2008), "Positive organizational behavior: engaged employees in flourishing organizations", Journal of Organizational Behavior, Vol. 29, pp. 147-54.

Bakker, A.B., Schaufeli, W.B., Leiter, M.P. and Taris, T.W. (2008), "Work engagement: an emerging concept in occupational health psychology", Work \& Stress, Vol. 22, pp. 187-200.

Brenninkmeijer, V. and Van Yperen, N. (2003), "How to conduct research on burnout: advantages and disadvantages of a unidimensional approach to burnout", Occupational and Environmental Medicine, Vol. 60, Suppl. 1, pp. 16-21.

Cherniss, C. and Kranz, D.L. (1983), "The ideological community as an antidote to burnout in the human services", in Farber, B.A. (Ed.), Stress and Burnout in the Human Services Professions, Pergamon, New York, NY, pp. 198-212.

Cho, J., Laschinger, H.K. and Wong, C. (2006), "Workplace empowerment, work engagement, and organizational commitment of new graduate nurses", Nursing Leadership, Vol. 19, pp. $43-60$.

Cooper, C.L. and Dewe, P. (2004), Stress: A Brief History, Blackwell, Malden, MA.

Demerouti, E., Bakker, A.B., Vardakou, I. and Kantas, A. (2002), "The convergent validity of two burnout instruments: a multitrait-multimethod analysis", European Journal of Psychological Assessment, Vol. 18, pp. 296-307.

Farber, B.A. (1983), "Introduction: A critical perspective on burnout”, in Farber, B.A. (Ed.), Stress and Burnout in the Human Services Professions, Pergamon, New York, NY, pp. 1-20.

Freudenberger, H.J. (1974), "Staff burnout”, Journal of Social Issues, Vol. 30, pp. 159-65.

Friberg, T. (2006), "Diagnosing burn-out: an anthropological study of a social concept in Sweden", Media Tryck, PhD thesis, Lund University, Lund.

Gellert, F.J. and Kuipers, B.S. (2008), "Short- and long-term consequences of age in work teams", Career Development International, Vol. 13 No. 2, pp. 132-49.

Golembiewski, R.T., Boudreau, R.T., Munzenrider, R.F. and Luo, H. (1996), Global Burnout: A Worldwide Pandemic Explored by the Phase Model, JAI Press, Greenwich, CT.

González-Romá, V., Schaufeli, W.B., Bakker, A. and Lloret, S. (2006), "Burnout and engagement: independent factors or opposite poles?”, Journal of Vocational Behavior, Vol. 68, pp. 165-74.

Halbesleben, J.R.B. and Buckley, M.R. (2004), "Burnout in organizational life", Journal of Management, Vol. 30, pp. 859-79.

Harter, J.K., Schmidt, F.L. and Hayes, T.L. (2002), "Business-unit-level relationship between employee satisfaction, employee engagement, and business outcomes: a meta-analysis", Journal of Applied Psychology, Vol. 87, pp. 268-79.

Hemingway, C.A. and Maclagan, P.W. (2004), "Managers' personal values as drivers of corporate social responsibility", Journal of Business Ethics, Vol. 50, pp. 33-44.

ICD-10 (1994), International Classification of Diseases, World Health Organization, Geneva.

Kristensen, T.S., Borritz, M., Villadsen, E. and Christensen, K.B. (2005), "The Copenhagen burnout inventory: a new tool for the assessment of burnout", Work \& Stress, Vol. 19, pp. 192-207. 
CDI

14,3

218

Kulkarni, G.K. (2006), "Burnout (Editorial)", Indian Journal of Occupational and Environmental Medicine, Vol. 10, pp. 3-4.

Lasch, C. (1979), The Culture of Narcissism: American Life in an Age of Diminishing Returns, Norton, New York, NY.

Leiter, M.P., Jackson, N.J. and Shaughnessy, K. (2008), "Contrasting burnout, turnover intention, control, value congruence, and knowledge sharing between Boomers and Generation X", Journal of Nursing Management, Vol. 16, pp. 1-10.

Loriol, M. (2002), “Mauvaise fatigue' et contrôle de soi: une approche sociohistorique ['Bad tiredness' and self-control: a sociohistorical approach]", Perspectives Interdisciplinaires sur le Travail et la Santé, Vol. 4, pp. 124-48.

Luthans, F. (2003), "Positive organizational behavior (POB): implications for leadership and HR development and motivation", in Steers, R.M., Porter, L.W. and Bigley, G.A. (Eds), Motivation and Leadership at Work, McGraw-Hill, New York, NY, pp. 178-95.

McDonald, P., Brown, K. and Bradley, L. (2005), "Have traditional career paths given way to protean ones? Evidence from senior managers in the Australian public sector", Career Development International, Vol. 10, pp. 109-29.

Martin, J. and Siehl, C. (1983), "Organizational culture and counterculture: an uneasy symbiosis”, Organizational Dynamics, Vol. 12, pp. 52-64.

Maslach, C. (1976), "Burned-out”, Human Behavior, Vol. 9, pp. 16-22.

Maslach, C. (1993), "Burnout: a multidimensional perspective”, in Schaufeli, W.B., Maslach, C. and Marek, T. (Eds), Professional Burnout: Recent Developments in Theory and Research, Taylor \& Francis, Washington, DC, pp. 19-32.

Maslach, C. and Jackson, S.E. (1981), "The measurement of experienced burnout”, Journal of Occupational Behavior, Vol. 2, pp. 99-113.

Maslach, C. and Leiter, M.P. (1997), The Truth about Burnout, Jossey-Bass, New York, NY.

Maslach, C. and Schaufeli, W.B. (1993), "Historical and conceptual development of burnout", in Schaufeli, W.B., Maslach, C. and Marek, T. (Eds), Professional Burnout: Recent Developments in Theory and Research, Taylor \& Francis, Washington, DC, pp. 1-16.

Maslach, C., Jackson, S.E. and Leiter, M.P. (1996), MBI: The Maslach Burnout Inventory: Manual, Consulting Psychologists Press, Palo Alto, CA.

Maslach, C., Leiter, M.P. and Schaufeli, W.B. (2008), "Measuring burnout", in Cooper, C.L. and Cartwright, S. (Eds), The Oxford Handbook of Organizational Wellbeing, Oxford University Press, Oxford, pp. 86-108.

Maslach, C., Schaufeli, W.B. and Leiter, M.P. (2001), "Job burnout”, Annual Review of Psychology, Vol. 52, pp. 397-422.

Perrewé, P.L., Hochwarter, W.A., Rossi, A.M., Wallace, A., Maignan, I., Castro, S.L., Ralston, D.A., Westman, M., Vollmer, G., Tang, M., Wan, P. and Van Deusen, C.A. (2002), “Are work stress relationships universal? A nine-region examination of role stressors, general self-efficacy, and burnout", Journal of International Management, Vol. 8, pp. 163-87.

Pines, A.M. (2003), "Occupational burnout: a cross-cultural Israeli Jewish-Arab perspective and its implications for career counselling", Career Development International, Vol. 8, pp. 97-106.

Pines, A. and Aronson, E. (1981), Burnout: From Tedium to Personal Growth, Free Press, New York, NY.

Potter, M.A., Gebbie, K.M. and Tilson, H. (2007), "The public health workforce”, in Novick, L.F., Morrow, C.B. and Mays, G.P. (Eds), Public Health Administration, Jones \& Bartlett, London, pp. 225-60. 
Roelofs, J., Verbraak, M., Keijsers, G.P.J., De Bruin, M.B.N. and Schmidt, A.J.M. (2005), "Psychometric properties of a Dutch version of the Maslach Burnout Inventory-General Survey (MBI-GS) in individuals with and without clinical burnout”, Stress and Health, Vol. 21, pp. 17-25.

Savicki, V. (2002), Burnout across Thirteen Cultures: Stress and Coping in Child and Youth Care Workers, Praeger, Westport, CT.

Schaufeli, W.B. (2006), "The balance of give and take: toward a social exchange model of burnout", The International Review of Social Psychology, Vol. 19, pp. 87-131.

Schaufeli, W.B. and Bakker, A.B. (2004), "Job demands, job resources and their relationship with burnout and engagement: a multi-sample study”, Journal of Organizational Behavior, Vol. 25, pp. 293-315.

Schaufeli, W.B. and Enzmann, D. (1998), The Burnout Companion to Study and Research: A Critical Analysis, Taylor \& Francis, London.

Schaufeli, W.B. and Salanova, M. (2007), "Work engagement: an emerging psychological concept and its implications for organizations", in Gilliland, S.W., Steiner, D.D. and Skarlicki, D.P. (Eds), Research in Social Issues in Management (Volume 5): Managing Social and Ethical Issues in Organizations, Information Age Publishers, Greenwich, CT, pp. 135-77.

Schaufeli, W.B., Bakker, A.B. and Van Rhenen, W. (in press), "How changes in job demands and resources predict burnout, work engagement, and sickness absenteeism", Journal of Organizational Behavior.

Schaufeli, W.B., Salanova, M., González-Romá, V. and Bakker, A.B. (2002), "The measurement of engagement and burnout: a confirmative analytic approach", Journal of Happiness Studies, Vol. 3, pp. 71-92.

Schaufeli, W.B., Bakker, A., Schaap, C., Kladler, A. and Hoogduin, C.A.L. (2001), "On the clinical validity of the Maslach Burnout Inventory and the Burnout Measure", Psychology \& Health, Vol. 16, pp. 565-82.

Seligman, M.E.P. and Csikszentmihalyi, M. (2000), "Positive psychology: an introduction", American Psychologist, Vol. 55, pp. 5-14.

Sennett, R. (1998), The Corrosion of Character: The Personal Consequences of Work in the New Capitalism, Norton, New York, NY.

Shirom, A. (1989), "Burnout in work organizations", in Cooper, C.L. and Robertson, I. (Eds), International Review of Industrial and Organizational Psychology, Wiley, New York, NY, pp. 25-48.

Shirom, A. and Melamed, S. (2005), "Does burnout affect physical health? A review of the evidence", in Antoniou, A.S.G. and Cooper, C.L. (Eds), Research Companion to Organizational Health Psychology, Edward Elgar, Cheltenham, pp. 599-622.

Turnipseed, D.L. and Turnipseed, P.H. (1997), "A bi-cultural analysis of the costs of caring: nursing burnout in the United States and the Philippines", Career Development International, Vol. 2, pp. 180-8.

Ulrich, D. (1997), Human Resource Champions, Harvard Business School Press, Boston, MA.

Van der Klink, J.J.L. and van Dijk, F.J.H. (2003), "Dutch practice guidelines for managing adjustment disorders in occupational and primary health care", Scandinavian Journal of Work Environment and Health, Vol. 29, pp. 478-87.

Van Emmerik, H. (2004), "For better or for worse? Adverse working conditions and the beneficial effects of mentoring", Career Development International, Vol. 9, pp. 358-73.

Work \& Stress (2005), "Special issue on the conceptualization and measurement of burnout", Work \& Stress, Vol. 20, pp. 187-267. 
CDI

14,3

220

\section{Further reading}

Enzmann, D. and Kleiber, D. (1989), Helfer-leider: Stress und Burnout in psychosozialen Berufen (Helper-ordeals: Stress and Burnout in the Human Services), Asanger, Heidelberg.

Schaufeli, W.B., Leiter, M.P., Maslach, Ch. and Jackson, S.E. (1996), "Maslach Burnout Inventory - general survey", in Maslach, Ch, Jackson, S.E. and Leiter, M.P. (Eds), The Maslach Burnout Inventory (3rd ed.) - Test Manual, Consulting Psychologists Press, Palo Alto, CA.

\section{About the authors}

Wilmar B. Schaufeli is Professor for Work and Organizational Psychology at Utrecht University, The Netherlands. He received his $\mathrm{PhD}$ from Groningen University and he is currently visiting professor at Loughborough Business School, UK, and Jaume I Universitat, Castellon, Spain. For almost three decades he has been an active and productive researcher in the field of occupational health psychology, publishing over 300 articles, chapters and books. Initially, his research interest was particularly on job stress and burnout, but in recent years this shifted towards positive occupational health issues such as work engagement. Dr Schaufeli is a licensed occupational health psychologist who has been actively involved in psychotherapeutic treatment of burned-out employees and is now engaged in organizational consultancy (www.c40b.nl). In addition, he held various managerial positions in (inter)national professional organizations. He is the corresponding author and can be contacted at: W.Schaufeli@uu.nl

Michael P. Leiter is Professor of Psychology at Acadia University in Canada and Director of the Center for Organizational Research \& Development that applies high quality research methods to human resource issues confronting organizations. He holds the Canada Research Chair in Occupational Health and Wellbeing at Acadia University. He is a registered psychologist in Nova Scotia, Canada. He received degrees in Psychology from Duke University (BA), Vanderbilt University (MA), and the University of Oregon (PhD). Dr Leiter has conducted research and written on job burnout throughout his career. Currently his research focuses on enhancing the quality of collegial relationships to enhance work engagement and to prevent burnout. He maintains international collaborations while maintaining an active involvement in applied research in his local region of Eastern Canada.

Christina Maslach is Vice Provost for Teaching and Learning, and Professor of Psychology at the University of California at Berkeley. She received her AB in Social Relations from Harvard-Radcliffe College in 1967, and her PhD in Psychology from Stanford University in 1971. She has conducted research in a number of areas within social and health psychology. However, she is best known as one of the pioneering researchers on job burnout, and has authored numerous books and articles, as well as the Maslach Burnout Inventory (MBI), the most widely used research measure in the burnout field. She has received several awards for her teaching, including national recognition as "Professor of the Year" in 1997, and was selected as a Fellow of the American Association for the Advancement of Science (which cited her "For groundbreaking work on the applications of social psychology to contemporary problems").

To purchase reprints of this article please e-mail: reprints@emeraldinsight.com Or visit our web site for further details: www.emeraldinsight.com/reprints 